\title{
CONSIDERAÇÓES SOBRE A ESTRATIGRAFIA DO GRUPO ACUNGUI (PROTEROZÓICO SUPERIOR), PARANÁ, SUL DO BRASIL
}

\author{
A.P.Fiori' \& L.A.Gaspar²
}

PALAVRAS-CHAVE: Grupo Açungui, Proterozóico, estratigrafia, tectônica.

FIORI, A.P.: GASPAR, L.A. (1993) Consideraç̋es sobre a estratigrafia do Grupo Açungui (Proterozóico Superior), Paraná, sul do Brasil, Bol.IG-USP, Sér.Clent., 24:1-19

\section{RESUMO}

A atual estratigrafia do Grupo Açungui não é original, mas resulta do empilhamento de fatias tectônicas como conseqüência do cavalgamento que ocorreu durante o fechamento da bacia. Cada fatia contém um ou mais conjuntos litológicos, com ordenaçảo estratigráfica regular, e que representam partes preservadas da coluna estratigrafica original.

O Grupo Açungui, do Proterozóico superior, compreende as formaçổes Capiru, Votuverava e Antinha, cada uma com pelo menos três conjuntos litológicos distintos, na maioria das vezes separados uns dos outros por falhas de cavalgamento. A primeira compreende os conjuntos Juruqui, Rio Branco e Morro Grande, a segunda, os conjuntos Bromado, Coloninha e Saivá e o terceiro, os conjuntos Tacaniça, Capivara e Vuturuvu.

Os conjuntos litológicos representam ambientes deposicionais os mais variados, desde plataforma com sedimentação carbonática, de águas bem rasas, até áreas de talude, com depósitos turbiditicos. O clima variou desde quente e úmido a glacial ou subglacial.

\section{ABSTRACT}

The stratigraphic order of the Açungui Group was significantly altered by thrust stacking of tectonic slices during basin closure. These slices presently show one or more regularly ordered internal lithological assemblages, which correspond to only a part of the original stratigraphic column.

In Parana, the Açungui Group is made up by the Capiru, Votuverava and Antinha Formations, each including three distinet lithologic assemblages, which are frequently limited by thrust faults. The Capiru Formation comprises the Juruqui, Rio Branco and Morro Grande assemblages; the Votuverava Formation comprises the Bromado, Coloninha and Saiva assemblages; and the Antinha Formation comprises the Tacaniça, Capivara and Vuturuvu assemblages.

The spectrum of lithologic assemblages shows contrasting depositional environments, from very shallow carbonate platform to continental slope with turbidite deposits. Climatic conditions varied from hot and wet to glacial or subglacial.

Departamento de Geologia, Universidade Federal do Paraní, Curitiba, Paraní, Brasil.
${ }^{2}$ Coavenaio UFPR-MINEROPAR. 


\section{INTRODUÇĀO}

O Grupo Açungui, na definição original (Bigarella \& Salamuni, 1958), é constituido pelas Formações Setuva, $\mathrm{Ca}$ piru e Votuverava, situando-se a primeira na base e a última no topo. Mais tarde, Marini et al. (1967), e Marini (1970) individualizaram outro pacote litológico, dentro do que era tido como Votuverava, ao qual atribuíram a denominação de Formação Água Clara. Posicionaram-no estratigraficamente sobre a Formação Votuverava, tendo por base os mergulhos generalizados para norte. Esses autores consideraram o Grupo Açungui de idade Proterozóica superior.

Com a evolução dos conhecimentos, esse quadro sofreu modificações substanciais a partir da década de 80. As Formaçōes Setuva e Água Clara foram redefinidas, e em função de seu grau metamórfico mais elevado e padrão estrutural mais complicado, foram consideradas mais antigas que o Grupo Açungui (Pontes, 1982; Fritzsons et al, 1982), e atribuidas ao Proterozóico médio. Permaneceram no Grupo apenas as Formações Capiru e Votuverava. Posteriormente, a porção da Formação Votuverava, situada imediatamente a norte da Falha de Morro Agudo, nas proximidades de Itaretama, PR, foi desmembrada, passando a constituir a Seqủência Antinha.

O termo "Sequêencia Antinha" foi proposto por Pontes (1982) para designar um pacote de metassedimentos clásticos, que considerou mais jovem que a Formação Votuverava, tendo em vista seu grau metamórfico mais baixo e padrão estrutural mais simples. Não incluiu nela, porém, os mármores calcíticos presentes na Serra do Vuturuvu, preferindo mantê-los na Formacão Votuverava, no que foi seguido por Soares (1987).

Por outro lado, Dias \& Salazar Jr. (1987), reestudando a Sequiência Antinha, mostraram que os mármores da Serra do Vuturuvu estão posicionados estratigraficamente sobre os metassedimentos clasticos. Dessa forma, incluiram-nos na Sequêencia Antinha, que por sua vez, a consideraram pertencente ao Grupo Açungui. Para Campanha et al. (1987) a Sequência Antinha inclui-se no Subgrupo Lajeado, definido no Estado de São Paulo, (Campanha et al., 1986), correspondendo à parte mais carbonática da Formação Votuverava clássica.

Neste trabalho, considera-se o Grupo Açungui composto pelas Formações Capiru, Votuverava e Antinha. Para a primeira mantém-se o seu significado original, incluindo todos os metassedimentos a sul da Falha da Lancinha; para a segunda, restringe-se sua designação de modo a englobar somente os metassedimentos ocorrentes entre as Falhas de Morro Agudo e da Lancinha (excluem-se aqueles da Sequeência Perau e da Formação Camarinha), enquanto para a terceira, mantém-se o mesmo sentido emprestado para a Sequência Antinha, por Dias \& Salazar Jr. (1987).

Empregar-se-á, aqui, ainda, o termo "formação" para as unidades Capiru, Votuverava e Antinha, mesmo que cada uma delas pudesse ser elevada à categoria de "grupo". Preferimos năo formalizar esta proposta até que se possa avaliar adequadamente a conveniência de transformar em "formações" os "conjuntos" aqui definidos.

\section{AS SUBDIVISÕES DO GRUPO ACYUN- GUI}

As Formaçøes Capiru, Votuverava e Antinha podem ser subdivididas em pelo menos nove conjuntos litológicos diferentes. As divisões feitas levam em conta tipos e associações de litologias, estruturas sedimentares, caracteristicas estruturais, as- 
pectos morfológicos e, principalmente, as falhas de cavalgamento, que quase sempre representam os limites de diferentes conjuntos litológicos.

A deformação do Grupo Açungui é heterogênea, havendo rochas muito deformadas ao lado de pouco deformadas. Nessas últimas, é possivel recuperar estruturas sedimentares, que aliadas a outras evidências, permitem discutir ambientes de sedimentação.

A Formação Capiru engloba todos os metassedimentos do Grupo Açungui a sul da Falha da Lancinha. Pode ser subdividida em pelo menos três conjuntos litológicos distintos, denominados de Juruqui, Rio Branco e Morro Grande (Fiori, 1991,
1992) (Fig.1). O Conjunto Juruqui compõe-se basicamente por filitos avermelhados, com intercalações não muito freqüentes de quartzitos, com exceção de uma área próxima a Bocaiúva do Sul. Já o Conjunto Rio Branco engloba mármores e/ou metacalcários e suas intercalaçōes de filitos e quartzitos. É o que apresenta maior extensão areal dentre os conjuntos litológicos da Formação Capiru, estando posicionado tectonicamente sobre a anterior, através das falhas da Colônia Venâncio e das Aranhas. O Conjunto Morro Grande caracteriza-se pela alternância de bancos ou camadas de quartzitos, filitos e mármores, com espessuras da ordem de centenas de metros. Os filitos e os mármores são geral-

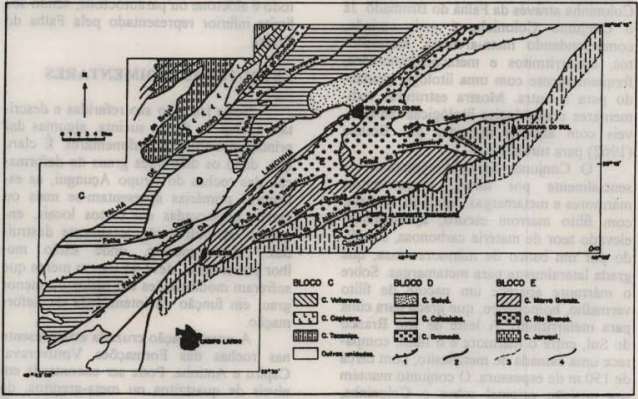

Figura 1 - Distribuição geográfica dos conjuntos litológicos integrantes do Grupo Açungui. C, D e E representam blocos tectônicos, separados pelas falhas de Morro Agudo e da Lancinha. 1. Falhas de cavalgamento, com o mergulho indicado pelos pequenos triângulos; 2. Falhas transcorrentes, com sentido de movimento indicado: 3. Limite aproximado Embasamento Cristalino/Grupo Açungui; 4. Contato entre conjuntos litológicos; 5. Falhas normais. 
mente bandados ou rítmicos e os quartzitos mais homogêneos. Posiciona-se tectonicamente sobre o Conjunto Rio Branco, através das falhas de Tranqueira-Pessegueiro.

A Formação Votuverava pode também ser subdividida em três conjuntos litológicos distintos, designados de Bromado, Coloninha e Saivá. Em termos areais, o segundo é o mais importante e caracteristico dessa formação (Fig. 1).

O Conjunto Bromado é composto por filitos, quartzitos e metaconglomerados polimíticos, que, inclusive, representam sua litologia mais caracteristica, aparecendo em camadas relativamente continuas, podendo atingir várias centenas de metros de espessura. Correlaciona-se com a Formação Iporanga (Leonardos, 1943), estando posicionado tectonicamente sobre o Conjunto Coloninha através da Falha do Bromado. Já - Conjunto Coloninha é mais variado, compreendendo meta-arenitos, metassiltitos, metarritmitos e metaconglomerados, frequientemente com uma litologia gradando para a outra. Mostra estruturas sedimentares e sequiências litológicas compativeis com aquelas definidas por Bouma (1962) para turbiditos.

O Conjunto Saivá é composto essencialmente por filitos, metarritmitos, mármores e metamargas. Inicia-se, na base, com filito marrom escuro, apresentando elevado teor de matéria carbonosa, sucedido por um banco de mármore cinza, que grada lateralmente para metamargas. Sobre - mármore aparece um pacote de filito vermelho, homogêneo, que grada para cima para metarritmito. A leste de Rio Branco do Sul, entre o mármore e o filito, comparece uma camada de metabasito, com cerca de $150 \mathrm{~m}$ de espessura. $\mathrm{O}$ conjunto mantém sua posição original sobre o Coloninha, pois não se caracterizou, com segurança, até o momento, contato tectônico entre ambos.

A Formação Antinha foi subdividida em três conjuntos litológicos, denominados de Tacaniça, Capivara e Vuturuvu (Fig. 1). $O$ primeiro engloba as rochas clásticas das unidades A e B de Dias \& Salazar Jr. (1987), constituidas respectivamente por metarritmitos silticos cinza, com intercalações de metassiltitos arenosos e metarritmitos siltico-arenosos, meta-arenitos, e metaconglomerados; o segundo, pelos metacalcários calcíticos, geralmente ritmicos e de coloração cinza escuro, da Unidade C, ou Carbonática, dos autores supramencionados, e o último, os metarritmitos arenosos, niveis de metaconglomerados, metassiltitos, quartzitos e meta-argilitos da unidade D. O empilhamento estratigráfico original parece estar preservado, pois não foram identificadas falhas nos limites entre os conjuntos acima. No entanto, a formação como um todo é alóctone ou parautóctone, sendo seu limite inferior representado pela Falha do Brejal.

\section{ESTRUTURAS SEDIMENTARES}

Neste trabalho são referidas e descritas, apenas de forma sucinta, algumas das principais estruturas sedimentares. É claro que, dado os diferentes graus de deformacão das rochas do Grupo Açungui, as estruturas primárias apresentam-se mais ou menos preservadas em certos locais, enquanto em outros são totalmente destruídas. Assim mesmo, onde estão melhor preservadas, deve-se ter em mente que sofreram modificaçōes em maior ou menor grau, em função da intensidade da deformação.

A estratificação cruzada está presente nas rochas das Formações Votuverava, Capiru e Antinha. Pode ser encontrada em níveis de quartzitos ou meta-arenitos, de filitos e de mármores e/ou metacalcários. É geralmente de pequeno porte, aparentemente com predominio da microestratificaçăo cruzada, que tem sua origem ligada a 
algumas formas de marcas onduladas. Estas últimas, por outro lado, são geralmente assimétricas, passando aos tipos de interferência, bem como a outros de aspecto anastomosado. Nos metacalcários, a estratificação cruzada é melhor evidenciada em superficies expostas, afetadas por dissolução diferencial, e, aparentemente, ocorre de preferência nas vizinhanças de biohermas estromatolíticos.

A estratificação gradacional é outra estrutura relativamente comum, presente principalmente nos metarritmitos e quartzitos das Formaçōes Capiru, Votuverava e Antinha. Nos metarritmitos do Conjunto Morro Grande, caracteriza-se pela alternância de niveis claros e escuros, de espessuras centimétricas, começando com metassiltitos arenosos ou meta-arenitos muito finos, impuros, de cores bem claras, gradando para meta-argilitos ou filitos carbonosos escuros. A gradação granulométrica é geralmente acompanhada também por uma gradação na cor dos sedimentos. Em muitos casos, pode-se observar que o nivel de granulometria mais grossa assenta-se sobre o de granulometria mais fina, de forma abrupta, através de um plano de contato, às vezes bastante irregular.

Também em meta-arenitos e quartzitos da Formação Votuverava, a estratificação gradacional pode ser facilmente detectada, sendo comum a passagem de metaarenitos grossos, às vezes conglomeráticos, a meta-arenitos finos e mesmo a metassiltitos. Nesse caso, os estratos são geralmente mais espessos, podendo atingir mais de 0,5 m. Igualmente, o estrato com a estratificação gradacional, assenta-se bruscamente sobre rochas mais finas, através de um plano geralmente irregular. $O$ topo apresentase frequentemente voltado para cima, havendo, no entanto, raros casos de inversão estratigráfica por processos tectônicos.

A estratificação ritmica está presente em grande parte dos conjuntos Coloninha $\mathrm{e}$
Morro Grande, consistindo na alternância de camadas de granulometria e cores (de intemperismo) variegadas, geralmente claras e vermelhas na primeira, e claras e cinza escuro na segunda, indicando ciclos regulares de sedimentação. Em muitos casos, verifica-se passagem gradacional de um nivel a outro, dentro dos metarritmitos, lembrando sequências depositadas por decantação; em outros casos, a passagem é caracterizada por uma brusca mudança na granulometria entre os diversos niveis. Quando relativamente bem preservados, pode-se encontrar microestratificaçäo cruzada, linsen, e até laminação convoluta dentro desses niveis.

A laminação convoluta indica movimentação dos sedimentos penecontemporaneamente à sua deposição, possivelmente devido a instabilidades tectônicas. Diferencia-se de dobras de origem tectônica porque a laminação convoluta encontra-se isolada entre dois estratos de laminação plano-paralela, não envolvidos na movimentação. Adicionais evidências de escorregamentos penecontemporâneos à deposição são dadas por falhas ou truncamentos de determinados niveis, situados entre estratos não perturbados, geralmente associados à laminação convoluta.

As brechas intraformacionais parecem restritas aos mármores e/ou metacalcários. Os fragmentos são geralmente angulosos ou sub-angulosos, denotando pequeno transporte. Não apresentam orientação definida e estão espalhados em matriz de granulação fina e de coloração escura. A espessura dos horizontes brechóides é reduzida, raramente ultrapassando 2 metros. Segundo Bigarella \& Salamuni (1956), desenvolveram-se gradativamente, a partir de gretas de contração dos sedimentos carbonáticos. Indicam no geral, pequenas quebras no processo normal de sedimentação, traduzidas por abaixamentos periódicos do nivel do mar, seguidas de ressecamento da 
superficie exposta, O material ressecado foi redepositado como uma camada de depósitos rudáceos de fragmentos achatados.

A "Brecha Calcária de Toquinhas", presente nos mármores do conjunto Saivá, é constituida por fragmentos angulosos, freqüentemente alongados, achatados $e$ esparsos numa matriz carbonática cinza. São provenientes da desagregação mecânica de filitos e de quartzitos, e são de dimensões bastante variadas, desde milimétricos, até cerca de 20 centímetros de comprimento. Bigarella (1947) estudou detalhadamente essa brecha, concluindo tratarse de um depósito de origem sedimentar, formado numa linha de costa de mar relativamente raso, ao pé de falésia.

Nos mármores onde ocorre esta brecha, como por exemplo, na pedreira da Votorantim, na saida de Rio Branco do Sul para Cerro Azul, pode-se observar niveis com granulometria grossa, compostos por grânulos ou fragmentos elipsoidais de mármore escuro. Há nítida granodecrescência dentro desses niveis, mais grossos na base e mais finos no topo, com o gradual desaparecimento dos grânulos. Suas espessuras sāo da ordem de 2 a $4 \mathrm{~cm}$, e sobre estes, aparecem niveis com estratificação plano paralela bem desenvolvida, sem a presença dos grânulos, e com espessuras de 3 a $5 \mathrm{~cm}$. A seguir, aparecem niveis com microestratificação cruzada, que são por sua vez, truncados por um outro nivel microconglomerático, reiniciando um novo ciclo. A espessura, desde a base do nivel grosso inferior até a base do nivel grosso superior, năo ultrapassa $10 \mathrm{~cm}$.

É possivel que essas feiçōes estejam ligadas a processos de sedimentação rápida, em épocas de tempestades. Nảo é possivel afirmar com segurança, mas, uma suave convexidade da estratificação, verificada nesse mesmo afloramento, associada à laminação cruzada de baixo ângulo, pode representar, conforme mencionado por
Duke (1985), estruturas do tipo hummocky cross-stratification. Durante periodos de tempestade, os grânulos são redepositados a profundidades maiores, muitos deles representando oóides formados em zonas menos profundas, próximo à costa, sob a açăo normal das ondas, e removidos durante esses periodos pela ação mais enérgica das ondas no fundo marinho.

As principais estruturas pisoliticasoolíticas foram observadas nos mármores da Sequêencia Capiru. Os pisóides possuem formato subesférico, geralmente orientados segundo o plano da foliação. As dimensões são variadas, com o eixo maior geralmente medindo mais de $2 \mathrm{~mm}$, podendo, em casos mais raros, atingir até $5 \mathrm{~mm}$. São melhor observados quando ressaltados pelo intemperismo e dissolução diferencial. Segundo Marini \& Bigarella (1967), essas estruturas, juntamente com os calcarenitos, formaramse em plataformas marinhas quentes, com poucos metros de profundidade, suficientemente movimentadas para permitir a aglutinação de grãos.

A estratificação plano-paralela é a mais abundante das estruturas primárias, presente em todos os conjuntos litológicos do Grupo Açungui. Pode ser reconhecida pela alternância de niveis com composições, cores, e espessuras diferentes, dentro de filitos, quartzitos e mármores. Intercalações entre esses três tipos litológicos são os casos mais evidentes; casos menos evidentes, mas muito comuns, são as intercalaçōes de quartzitos, filitos e mesmo de mármores, em bancos mais espessos do mesmo tipo litológico, com as diferenças evidenciadas por variaçōes granulométricas e/ou de coloração.

As principais estruturas estromatoliticas estão restritas aos mármores do Conjunto Rio Branco, que em alguns casos mostram crescimento concêntrico, às vezes com forma cilindrica bem desenvolvida, e em outros, forma algo irregular. Para 
Salamuni \& Bigarella (1967), essas estruturas apresentam-se levemente deprimidas em sua parte central, enquanto as margens são pronunciadamente convexas. São constituidas de lâminas claras e escuras, alternadas, com aparência rítmica. As análises processadas por esses autores mostraram que as lâminas escuras apresentam certa percentagem de substância grafitosa.

\section{CONSIDERAÇÕES SOBRE OS AM- BIENTES DEPOSICIONAIS}

O estudo do ambiente de deposição de rochas sedimentares é, no geral, um assunto bastante complexo. Essa complexidade torna-se ainda maior, quando se pretende interpretar o ambiente de deposição de uma sequêencia de rochas afetadas por metamorfismo regional e por uma tectônica de cavalgamento, que nảo só obstruiram as estruturas primárias, como também alteraram a sucessão estratigrafica original. Não obstante essas dificuldades, é possivel esboçar uma tentativa de interpretação ambiental, tendo-se por base certas evidências, como estruturas organógenas, estruturas e texturas sedimentares, associaçōes litológicas, etc.

A maioria dos autores que discutiram - ambiente de deposição das rochas do Grupo Açungui admite condições marinhas de deposição (Moraes Rego, 1931; Oliveira \& Leonardos, 1943; Almeida, 1944, 1956; Maack, 1947; Bigarella, 1947; Melfi et al., 1965; Marini et al., 1967; Bigarella \& Salamuni, 1959, 1967; Marini, 1970; Scholl, 1981), Outros autores, como Petri \& Suguio (1969), também admitem ambiente marinho para a deposição da maior parte do Grupo Açungui, fazendo entretanto restrições aos metassedimentos situados a norte do Granito de Ribeirão Branco, no Estado de São Paulo, para os quais sugerem deposição em ambiente misto e talvez continental.
Na realidade, a espessura, natureza e estrutura dos metassedimentos, bem como a existência de calcários organógenos e bioclásticos, deixam poucas dúvidas quanto à origem marinha das rochas do Grupo Açungui. Por outro lado, a presença de sedimentos intensamente dobrados, afetados por uma tectônica de cavalgamento, com metamorfismo e magmatismo associados, indica desenvolvimento em condiçōes geossinclinais.

Muito embora não se tenham ainda encontrado restos orgânicos preservados, a presença de folhelhos carbonosos, em alguns niveis do Grupo Açungui, é uma evidência inegável da atividade biológica vigente à época da deposição. Essa atividade é reforçada pela existência de estromatólitos encontrados nos dolomitos, e de grande importância para a determinação da gênese e ambiente de deposição.

A maioria dos autores admite que as estruturas estromatoliticas se formam na regiāo inter-maré e, ocasionalmente, na zona supra-maré. (Logan et al., 1964; Friedman \& Sanders, 1967; Taft, 1967; Hoffman, 1967; Kendall \& Skipwith, 1968; Hofmann, 1969; Hoffman, 1974; Hoffman, 1976; Cecile \& Campbell, 1978; Shinn, 1983; James, 1983). Os estromatólitos da Formação Capin foram classificados no tipo SH-C por Marini \& Bosio (1969) e ao que parece, estruturas desse tipo são formadas em regiões de inter-marés de praias abertas, onde a forte movimentação das águas inibe o crescimento de ligações laterais entre as estruturas ou removem-nas logo após a sua formação. Para Almeida (1944), as biohermas estromatoliticas deviam cobrir extensa área do fundo do mar (provavelmente um mar epicontinental), o qual, à medida que crescia a espessura dos recifes, sofria lenta e gradual subsidência, permitindo a permanência das algas na zona fótica. Talvez a principal condição necessária para o desenvolvimento das 
biohermas tenha sido a limpidez da água. Estromatólitos pequenos (Fairchild, 1982) foram descritos na Formação Capiru, próximo à gruta de Bacaetava (flanco norte da Sinforma de Morro Grande) e na pedreira da Calfibra (flanco norte da Antiforma do Setuva), e representam um novo tipo, característico dessa formação. Ocorrem associados a brechas intraformacionais e indicam condições de sedimentaçăo em águas rasas, possivelmente em ambiente de intermaré de baixa energia, com ação de correntes suaves (Fairchild, 1982).

A presença relativamente comum de pisóides e oóides nos mármores da área, é outra importante prova das condiçôes ambientais vigentes à época da deposição dessas rochas. Para Bigarella \& Salamuni (1956), devem ter-se formado em águas relativamente movimentadas, com ondas e correntes, sendo esta hipótese corroborada pela existência de estratificação cruzada em alguns horizontes de dolomitos, tanto superiores como inferiores aos horizontes pisolítico-oolíticos.

Embora não haja dúvida quanto à origem biohermal de parte dos meta-dolomitos do Conjunto Rio Branco, em virtude da presença de estruturas estromatoliticas, parece que grande parte desses sedimentos, é na verdade, de origem clástica, como já observaram Bigarella \& Salamuni (1956). Dessa forma, dolomitos estratificados e não fossiliferos, com presença de oóides-pisóides e estratificação cruzada, poderiam tanto ter derivado da ação mecânica de ondas sobre biohermas, como da autobrechação de sedimentos por ressecamento. Os detritos seriam redistribuidos pelas correntes, formando depósitos puramente clásticos.

Outra questão importante, diz respeito à presença de corpos lenticulares de quartzitos e de filitos, de dimensōes muito variadas, intercalados nos metadolomitos do Conjunto Rio Branco. Para Petri \&
Suguio (1969), a deposição de calcário quase puro em planicies de maré, implica na ausência de grandes rios que transportam material terrigeno. Por isso, a ação de complexas correntes marinhas, longitudinais à costa, foram evocadas por esses autores para explicar o contato direto de depósitos de calcário e de arenitos ou siltitos/argilitos, em padrões intrincados, como os verificados na área.

Parece mais provável, entretanto, a nosso ver, que essas intercalações estejam relacionadas a mudanças do nivel do mar. Em periodos de mar alto, desenvolvem-se os bancos de calcário por ação de cianoficeas, e em periodos de mar baixo, se dá a exposição e erosão dos sedimentos carbonáticos, acompanhada da progradação da sedimentação terrígena por sobre os bancos de calcário, que inclusive, alimentaria depósitos de águas mais profundas, posicionados à frente. Durante esses periodos, as biohermas são erodidas e redepositadas nas imediações, originando depósitos essencialmente clásticos.

Os mármores da Formação Antinha (Conjunto Capivara) são geralmente de cor escura e piritosos, indicando ambiente deposicional anaeróbico. Aliado a esse fato, a ausência de estruturas estromatolíticas parece indicar ambiente mais profundo para a sua deposição, ao menos abaixo da zona fótica.

Já para os espessos pacotes de filitos e metassiltitos do Conjunto Coloninha, pode-se inferir uma maior profundidade da água, em ambiente neritico ou batial. Essa informação é dada principalmente pelos metarritmitos, com estrutura gradacional e matriz argilosa abundante, que constituem a litologia dominante da referida sequência.

E comum encontrar nos metassedimentos do Conjunto Coloninha pouco deformados, microestratificação cruzada e laminação convoluta concentradas em niveis, dentro de metarritmitos, além de gra- 
nodecrescência e contatos abruptos de niveis grossos, alguns até conglomeráticos, sobre finos. Essas feiçōes são típicas de depósitos de correntes de turbidez, É possivel que se tratem de turbiditos e os intervalos (Bouma, 1962) mais freqüentemente observados são o a-b, a-b-c, b-c-d/e, sendo raros os mais completos.

As lentes de metaconglomerados oligomíticos, com estratificação gradacional, que ocorrem junto com metarritmitos na parte inferior do Conjunto Coloninha, poderiam ter-se formado por correntes de turbidez proximais, de alta densidade, ou por deslizes subaquáticos, como mencionam Petri \& Suguio (1969).

A estratificação cruzada, do tipo tangencial na base, de médio porte, em corpos lenticulares de meta-arenitos grossos e/ou metaconglomerados que gradam para cima a sedimentos mais finos, com sequeencias incompletas de Bouma, associados a canais escavados em metassiltitos ou meta-arenitos finos, leva a supor que os turbiditos grossos da base do Conjunto Coloninha representem depósitos de canais submarinos, entalhados em zona de talude continental, e portanto, formados em águas relativamente profundas (Shepard, 1981; Morris \& Busby-Spera, 1988; Bueno, 1988; Bruhn \& Moraes, 1989). Significativa nesse sentido é a presença de brechas com fragmentos angulosos de sedimentos finos do próprio Conjunto Coloninha, de tamanhos variáveis, alguns atingindo $30 \mathrm{~cm}$ de comprimento, produzidos pela intensa erosão do substrato sedimentar e pelo colapso dos canais escavados por correntes de turbidez de alta densidade. $O$ sentido de movimento local da corrente, tendo-se por base a estratificação cruzada, é de noroeste para sudeste.

Camadas delgadas de óxidos de ferro, ainda que não sejam abundantes, podem ser encontradas no Conjunto Juruqui, e fornecem indicações adicionais acerca do ambiente de deposição. Para James (1954) a hematita se deposita como óxido de ferro hidratado em aguas rasas, bem arejadas.

Tendo-se em conta os aspectos acima discutidos, e considerando-se a distribuição espacial dos conjuntos, suas variações laterais e a estruturação da área (ver p.ex. Fiori, 1991, 1992), tem-se os seguintes ambientes deposicionais para os diferentes conjuntos litológicos

a. Conjunto Juruqui - posiciona-se na parte inferior da Formação Capiru, bordejando todo o limite com o Embasamento Cristalino, numa faixa relativamente estreita, de direção nordeste (Fig.1). Nas proximidades de Bocaiúva do Sul, apresenta um fäcies constituido essencialmente por quartzitos, com intercalaçōes de filitos e metarritmitos, e algumas lentes restritas de mármore. Nesse local, os quartzitos representam a litologia dominante e variam em granulometria, desde grossos a finos, mas com predominio dos primeiros. Não é rara a presença de niveis granodecrescentes, granocrescentes, estratificação cruzada e planoparalela. Os filitos intercalados são geralmente maciços, e apresentam uma fração arenosa, quando próximos a camadas de quartzitos. Mais raramente, apresentamse na forma de metarritmitos. Todo esse conjunto grada para filitos e metarritmitos para sudoeste, a partir de Bocaiúva do Sul, sendo cada vez mais rara a presença de corpos arenosos intercalados. Ao mesmo tempo, a granulometria dos quartzitos vai se tornando gradualmente mais fina para sudoeste. Ao que parece, este conjunto representa um leque deltáico, com fácies de frente deltáica nas imediaçōes de Bocaiúva do Sul, e de prodelta, na parte sudoeste da área.

b. Conjunto Rio Branco - a presença de estromatólitos, oóides, estratificação cruzada, brechas intraformacionais, fendas de ressecamento, marcas onduladas e bancos de mármore de origem clástica, deriva- 
dos da ação mecânica de ondas sobre biohermas, parecem deixar poucas dúvidas quanto ao ambiente marinho raso em que se formaram, caracterizando uma costa de sedimentação carbonática, inclusive com ação de marés e de ondas. O suprimento de sedimentos terrígenos era extremamente reduzido, sendo essa monotonia quebrada de quando em quando por abaixamentos do nível do mar, que permitia a formação de depósitos pelíticos e arenosos, intercalados aos mármores. O continente deveria estar extremamente arrasado nessa época, e o clima vigente era provavelmente quente e úmido.

c. Conjunto Morro Grande - a caracteristica principal desse conjunto é a intercalação de bancos de quartzitos e de metarritmitos, estes com abundante matéria carbonosa. Nessas rochas é comum a presença de microestratificação cruzada, estratificação gradacional, estruturas do tipo linsen, laminação planoparalela e, inclusive, feições do tipo hummocky cross-stratification. Na sua parte inferior, ocorrem duas camadas de mármore/metacalcário dolomitico, separadas por um banco de quartzito (Fig. 2), sendo que a inferior, próximo à atual base, apresenta abundantes estromatólitos colunares. Aparentemente, o conjunto todo formou-se em condições

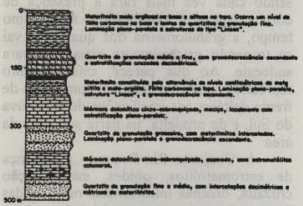

Figura 2 - Coluna litoestratigráfica do Conjunto Morro Grande. plataformais, no inicio em ambiente marinho raso, com predomínio de sedimentação carbonática, e mais tarde, em condições de águas mais profundas e calmas, com depósitos de metarritmitos e barras de plataforma, periodicamente afetados por tempestades.

d. Conjunto Bromado - os metaconglomerados representam a litologia mais caracteristica desse conjunto. Aparecem em corpos de espessuras variáveis, com o maior deles atingindo várias centenas de metros, e com grande continuidade lateral. A matriz é pelítica a arenosa, mas em alguns casos, é praticamente ausente. Os clastos variam em dimensão, desde grânulos a matacōes com mais de $50 \mathrm{~cm}$ de comprimento. A péssima seleção, a grande variedade composicional, o pouco retrabalhamento, e a presença de seixos facetados e estriados ao lado de matacões indicam tratar-se de um diamictito, depositado em corpo aquoso, próximo a geleiras. É possível que esteja relacionado com uma das extensas glaciações ocorridas no Proterozóico Superior, compreendido num periodo de 950 a 615 Ma. (Hallam, 1987, p. 164).

e. Conjunto Coloninha - a caracteristica principal desse conjunto são as seqüências Bouma (Bouma, 1962). Os turbiditos mais grossos ou proximais, inclusive com feições de depósitos relacionados a possiveis canais submarinos, ocorrem na porção inferior do conjunto, enquanto na parte média, predominam as fácies mais distais, sendo comuns os intervalos b-c-d/e de Bouma. Na parte superior, aparece um corpo de filito bastante espesso, com raras evidências de estratificação paralela e microestratificação cruzada, sugerindo deposição muito rápida a partir de suspensões altamente concentradas.

Provavelmente, esse conjunto representa depósitos realizados em águas profundas. Paralelamente, estruturas de escor- 
regamento ou movimentação de massa sinsedimentar são feições comuns na sua parte media e inferior, evidenciando periodos de maior instabilidade da bacia.

f. Conjunto Saivá - segundo Scholl (1981), o ambiente de deposição das rochas do seu Subconjunto AI, que em grande parte corresponde ao Conjunto Saivá, é o de águas calmas, com os carbonatos indicando ambiente restrito, passando a euxinico. A laminação planoparalela e a escassez. de outras estruturas sedimentares levou 0 referido autor a supor que a deposição ocorria abaixo do nivel das ondas (60-80 m), mas a julgar pelos carbonatos, a profundidades não superiores a $800 \mathrm{~m}$. A presença de estruturas do tipo hummocky cross-stratification, ao lado de brechas intraformacionais, evidencia que os sedimentos eram ocasionalmente afetados por tempestades.

g. O Conjunto Tacaniça - com metarritmitos intercalados a meta-arenitos, exibindo microestatificação cruzada acanalada, laminação convoluta e estratificação gradacional, além da presença de metaconglomerados monomiticos, e predominio de cores avermelhadas, assemelha-se ao Conjunto Coloninha anteriormente descrito. Há contribuição de correntes de turbidez no processo deposicional desse conjunto.

h. Conjunto Capivara - é composto essencialmente por metacalcário cinza escuro, bandado, com freqüentes intercalaఢ̧̃es de material carbonático argiloso impuro. A ausência de estruturas sedimentares como microestratificação cruzada, oóides, estruturas estromatolíticas, etc., aliada à ge-neralizada cor escura do metacalcário e presença relativamente comum de pirita, leva a supor ambiente de deposição em águas profundas, pouco movimentadas, e redutoras.

i. Conjunto Vuturuvu - engloba metarritmitos arenosos, com intercalaçōes de niveis metaconglomeráticos, metassiltitos e meta-argilitos. Estruturas sedimentares, como laminação planoparalela e estratificação gradacional, são freqüentes nessa unidade. Os estratos, em geral, iniciam-se por uma parte grossa (meta-arenito grosso, às vezes feldspático, metaconglomerado, etc.) e gradam para meta-arenitos maturos, metassiltitos e meta-argilitos.

A estratificação gradacional $\mathrm{e}$ a estratificação ritmica parecem indicar tratarse de um turbidito. E possivel que represente depósito de águas relativamente profundas, com aporte periódico de grande quantidade de detritos transportados por fluxo (Pontes, 1981).

\section{TENTATIVA DE CORRELAÇĀO ES- TRATIGRÁFICA}

As relaçōes estratigráficas entre as diversas formações do Grupo Açungui sempre foram problemáticas, e até o momento, não se chegou a uma solução definitiva. Bigarella \& Salamuni (1958) posicionaram a Formação Votuverava estratigraficamente sobre a Capin, com base no mergulho de ambas para noroeste, na região a norte da Antiforma do Setuva. Porém, os autores desconheciam a existência da Falha da Lancinha que separa as duas. Mais tarde, Marini et al. (1967), após a individualização da Formação Água Clara, mantiveram a Formação Setuva na base do Grupo Açungui, seguida das formações Capiru e Votuverava, com a Água Clara no topo, e nesse sentido foram seguidos por Salamuni \& Bigarella (1967). Da mesma forma, esses autores se basearam no generalizado mergulho para noroeste das camadas, não tendo reconhecido na época, a presença da Falha de Morro Agudo separando as formações Votuverava e Ảgua Clara.

A seguir, surgiram hipóteses de disposição lateral das formações Capiru e Vo- 
tuverava, com depósitos consequientemente contemporâneos (Petri \& Suguio, 1969; Ebert, 1971). Scholl et al. (1980) aventaram inclusive, a possibilidade de interdigitação entre ambas na altura de Bocaiúva do Sul, quando então identificaram as "Fácies Votuverava e Capiru".

Posteriormente, Pontes (1981, 1982) mostrou que a Formação Água Clara posiciona-se não no topo, mas na base do Grupo Açungui, sugerindo a possibilidade desta ter-se desenvolvido em um ciclo geotectônico anterior àquele do Grupo Açungui. Nesse mesmo sentido foi seguido por Fritzsons et al. (1982) que incluiram a Formação Água Clara no Grupo Setuva (a Formação Setuva dos autores anteriores passou a fazer parte desse Grupo), e consideraram-no de um ciclo geotectônico mais antigo.

A verdade é que as referidas unidades estão separadas por falhamentos e, algumas vezes, com áreas aflorantes bastante distanciadas geograficamente, 0 que dificulta a investigação das relaçőes estratigráficas originais. Na Antiforma do Setuva, o contato entre as Formaçōes Capiru e Setuva é tectônico, através da falha de cavalgamento do Queimadinho (Fiori, 1991, 1992). No Núcleo Betara, aflora a Formação Perau (atribuída ao Grupo Setuva), porém, o contato entre esta e a Votuverava é também tectônico, através da falha de cavalgamento do Betara (Fiori, 1991, 1992), faltando inclusive entre ambas, a Formação Capiru.

O contato entre as Formaç̃es Capiru e Votuverava é feito através da Falha da Lancinha, cujo deslocamento direcional é presumivelmente superior a uma centena de quilômetros (Fiori, 1985) e assim, os tratos de ambas, ora adjacentes, deveriam originalmente se posicionar a uma distância equivalente. $\mathrm{O}$ contato entre as Formações Votuverava e Antinha (esta última era tida anteriormente como extensão da Formação Votuverava) é igualmente tectônico, atra- vés da Falha de Morro Agudo, com deslocamento direcional de mais de uma centena de quilômetros (Fiori, 1985). O contato entre as Formações Água Clara e Antinha é tectônico, através da falha de cavalgamento do Brejal.

No presente trabalho, é feita uma nova tentativa para solucionar esse problema, levando-se em conta o padrão estrutural, o papel desempenhado pelas falhas de cavalgamento e transcorrentes, os ambientes deposicionais, e as comparações entre os conjuntos litológicos.

Os metassedimentos avermelhados do Conjunto Bromado e Coloninha são típicos da Formação Votuverava e muito semelhantes aos filitos avermelhados do Conjunto Juruqui. Isto é tanto verdade que Scholl et al. (1980) consideraram estes últimos como "Fácies Votuverava", dentro da Formação Capiru. Da mesma forma, o Conjunto Tacaniça assemelha-se aos conjuntos Bromado e Coloninha, tanto que originalmente esses metassedimentos pertenciam à Formação Votuverava. Por outro lado, o Conjunto Juruqui posiciona-se na parte inferior da Formação Capiru, em contato com gnaisses e migmatitos do Embasamento Cristalino enquanto o Conjunto Coloninha posiciona-se sobre gnaisses e quartzitos dos Grupos Setuva e Complexo Pré-Setuva, que representam o embasamento do Grupo Açungui no local. O Conjunto Tacaniça posiciona-se sobre rochas da Formação Agua Clara, que representa o embasamento do Grupo Açungui, naquele local. Os contatos são todos tectônicos, através de falhas de cavalgamento, implicando em aloctonia generalizada para o Grupo Açungui.

No Bloco Tectônico D, limitado pelas Falhas da Lancinha e de Morro Agudo (Fig. 1), os conjuntos Bromado, Coloninha e Saivá podem ser estratigraficamente organizados nessa mesma ordem, de baixo para cima, e, como um todo, constituem a 
Formação Votuverava. O Conjunto Bromado representa depositos com contribuiç̃o glacial, enquanto o Juruqui representa depósitos deltáicos, e pode representar o inicio da deposição do Grupo Açungui, na área estudada.

Por outro lado, os conjuntos Coloninha e Tacaniça, cujo mecanismo principal de deposição é o de correntes de turbidez, podem se correlacionar à distância. Esta correlação encontra maior suporte, considerando-se a parte média do Conjunto Coloninha, com predomínio dos intervalos b-c-d/e de Bouma, e ausência de turbiditos proximais no Conjunto Tacaniça. Indicam um rápido aprofundamento e alargamento da Bacia Açungui, porém, na secção do Conjunto Coloninha falta sua parte inferior, truncada por falha.

O Conjunto Saivá posiciona-se sobre o Conjunto Coloninha, aparentemente através de contato normal. Não encontra correlação com outros conjuntos na área estudada, e parece indicar condições de relativa estabilidade da bacia.

O Conjunto Rio Branco representa um pacote de mármore relativamente espesso, depositado em ambiente costeiro, de águas bem rasas, com presença de estromatólitos e intercalaçōes lenticulares de quartzitos e filitos. Por outro lado, o Conjunto Morro Grande apresenta, em sua parte inferior, duas camadas de mármore dolomítico, a mais antiga com abundantes estruturas estromatoliticas. É possivel que essas duas camadas correspondam a prolongamentos do Conjunto Rio Branco, para dentro da bacia, conforme representado na Figura 3.

Durante os periodos de abaixamento do nível do mar, advém o processo de erosão das biohermas, com concomitante redeposição de calcário clástico, e progradação da sedimentação terrigena, originando as intercalações de quartzitos e filitos pelas sucessivas variações do nivel do mar. Co-

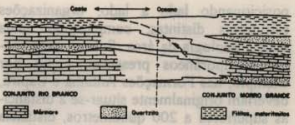

Figura 3 - Relação estratigráfica esquemática cntre - Conjunto Rio Branco e o Conjunto Morro Grande. A linha tracejada representa o sítio da futura Falha de Tranqueira/Pessegueiro, com sentido de movimento indicado.

mo discutido antes, é possivel que a deposição dos sedimentos em condiçōes de águas mais profundas, situadas além da plataforma carbonática, seja consequência do mesmo fenômeno da flutuação do nivel do mar, responsável também pelas intercalações nos mármores. Essas intercalações corresponderiam, pois, a superficies erosivas, esculpidas na plataforma carbonática, por sobre as quais passaram os sedimentos que alimentaram a deposição do Conjunto Morro Grande, em águas mais profundas. Há evidências de rápido aporte de material terrigeno, seguido de sedimentação por decantação, originando os metarritmitos gradacionais desse conjunto.

Posteriormente, com o fechamento da bacia, os depósitos do Conjunto Morro Grande foram tectonicamente posicionados sobre os mármores do Conjunto Rio Bran$\mathrm{co}$, através do efeito combinado das Falhas de Tranqueira e do Pessegueiro (Fig. 3).

Nunca é demais ressaltar que os conjuntos não podem ser relacionados entre si, ignorando-se as falhas de cavalgamento e de transcorrência que recortaram a área. As primeiras truncaram a coluna estratigráfica original em fatias, transportando-as à distância e empilhando-as, colocando lado a lado, subambientes deposicionais antes separados por grandes distâncias. As segundas, por sua vez, recortaram o empilhamento tectônico anterior, 
posicionando lado a lado, organizações estruturais distintas, complicando ainda mais a geologia da área. Subambientes penecontemporâneos presentes, como por exemplo, nas Formações Antinha e Capiru, deveriam originalmente situar-se a distâncias superiores a 200 quilômetros, distância esta que corresponde somente ao deslocamento acumulado das Falhas da Lancinha e de Morro Agudo. Este fato, por si só, já dificulta en muito, qualquer tentativa de correlação, e conseqüentemente, da reconstituição da paleogeografia da Bacia Açungui.

\section{PROVÁVEL GEOMETRIA DO GRU- PO ACUNGUI ANTES DA SUA DE- FORMAÇÃO}

A organização estrutural da Formação Capiru, é na forma de duplex (Fiori, 1991, 1992), como mostrado na Figura 4.1. Deslocando-se as diferentes fatias tectônicas em sentido contrário ao movimento principal das falhas de cavalgamento, de forma a justapor as rampas assinaladas com as mesmas letras, que representam secçōes originalmente contiguas, obtém-se a organização estratigráfica como mostrada na Figura 4.3. A Figura 4.2 representa um estágio intermediário nesse processo de retirada da deformação, após a eliminação dos efeitos da Falha do Pessegueiro.

O Conjunto Juruqui, conforme discutido anteriormente, marca o inicio da sedimentação na Bacia Açungui, no Bloco Tectônico E, com depósitos de natureza deltáica. Segue-se o pacote de mármores do Conjunto Rio Branco, essencialmente litorâneos, interdigitados mais para o interior da bacia, com depósitos plataformais do Conjunto Morro Grande. É possivel que as duas camadas de mármore, uma das quais estromatolítica, presentes na parte inferior do Conjunto Morro Grande, representem, na verdade, interdigitaçőes com o

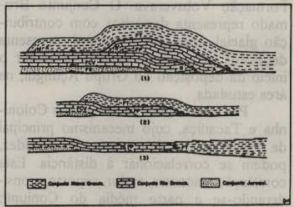

Figura 4 - Reconstituiçăo da estratigrafia original do Grupo Açungui (Formaçăo Capinu). (1) organizaçăo estrutural atual; (2) sccção após a retirada do efeito da Falha do Pessegueiro (FP); (3) organizaçăo estratigráfica antes do evento de cavalgamento. FT = Falha de Tranqueira; FCV = Falha da Colônia Venânció; FS = Falha do Setuva. A-A' e B-B' representam rampas inicialmente contiguas, respectivamente. (Figuras sem escala).

Conjunto Rio Branco, como sugerido na Figura 3.

A organização estrutural da Formação Votuverava, se dá segundo o modelo de duplex apresentado na Figura 5.1 (Fiori, 1991, 1992). Procedendo-se à retirada dos efeitos das Falhas do Bromado e de Votuverava, obtém-se a organização estratigráfica mostrada na Figura 5.2. Nesse bloco tectônico (Bloco D), o Conjunto Bromado representa o início da deposição do Grupo Açungui, com contribuição glacial. A seguir, a bacia aprofunda-se rapidamente, permitindo a deposição do Conjunto Coloninha, com importante contribuição de correntes de turbidez. O Conjunto Saivá vem a seguir, indicando condiçôes de maior estabilidade da bacia, com predominio de águas de profundidade média.

A organização estratigráfica da Formação Antinha está preservada, de vez que não foi atingida internamente pelos cavalgamentos. Inicia-se na base com o Conjunto Tacaniça, seguindo-se para cima, os conjuntos Capivara e Vuturuvu, respecti- 


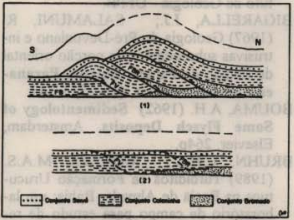

Figura 5 - Reconstituição da estratigrafia original do Grupo Açungui (Formação Votuverava). (1) organizaçăo estnutural atual; (2) secção antes do evento de cavalgamento, com localizaçào das futuras falhas. $\mathrm{FBR}=$ Falha do Bromado; FV $=$ Falha de Votuverava; $\mathrm{FB}=$ Falha do Betara. (Figuras scm escala).

vamente.

As três secç̃es estudadas das Formações Capiru, Votuverava e Antinha representam partes da coluna estratigráfica original da Bacia Açungui. Em outras áreas, podem aparecer porções diferentes dessa mesma coluna, que analisadas em conjunto, permitirão o melhor entendimento da natureza, paleogeografia e evolução da Bacia Açungui.

\section{CONCLUSÕES}

\section{O Grupo Açungui é composto pelas} Formaçōes Capiru, Votuverava e Antinha. Cada uma, entretanto, compõe-se de pelo menos três conjuntos litológicos distintos. A primeira compreende os conjuntos Juruqui, Rio Branco e Morro Grande; a segunda, os conjuntos Bromado, Coloninha e Saivá e a terceira, os conjuntos Tacaniça, Capivara e Vuturuvu. A maioria deles está separadas por falhas de cavalgamento. Cada um contém parte da coluna estratigráfica original, e como consequência, o Grupo Açungui exibe uma estratigrafia que não é original, e sim o resultado de empilhamento tectônico.

O Conjunto Juruqui evidencia ambientes mistos de deposição, com provável delta ou leque deltáico na região de Bocaiúva do Sul; o Conjunto Rio Branco, sedimentação em costa carbonatica, em águas rasas; o Conjunto Morro Grande, sedimentação em área de plataforma, em condiçōes de relativa estabilidade da bacia marinha; o Conjunto Bromado registra atividade glacial; o Conjunto Coloninha representa essencialmente depósitos de turbidez, sendo que turbiditos proximais, com canais submarinos, aparecem em sua parte inferior, e os turbiditos distais, em sua parte média a superior. O Conjunto Saivá parece indicar condições de maior estabilidade da bacia, com depósitos de águas relativamente calmas e de profundidades médias.

A Formação Antinha mantém sua organização estratigráfica original, porém, é autóctone ou parautóctone. O Conjunto Tacaniça, que representa sua parte inferior, evidencia depósitos com atividades de turbidez; o Conjunto Capivara, com deposição essencialmente carbonática, indica águas relativamente profundas, em condições redutoras; e o Conjunto Vuturuvu, novamente condiçōes de turbidez, com depósitos imaturos.

Os conjuntos Juruqui e Bromado marcam o inicio da deposição na Bacia Açungui, porém, representam subambientes distintos. Os conjuntos Rio Branco e Morro Grande podem ser penecontemporâneos, com o primeiro depositado junto à zona costeira, e o segundo, em zonas de plataforma, em águas mais profundas. O Conjunto Tacaniça parece se correlacionar com a parte média do Conjunto Coloninha, enquanto os demais não encontram correlação entre si na presente área de estudo.

\section{AGRADECIMENTOS}


O presente trabalho foi viabilizado graças ao suporte financeiro oferecido pela Mineropar - Minerais do Paraná S/A, e pela FINEP/PADCT, contrato $n^{\circ} 43.89 .00 .41$. 00 . Os autores registram seus agradecimentos aos professores Paulo C.Soares e Elimar Trein, pelas discussōes, que muito ajudaram a melhorar o trabalho. Agradecimentos especiais aos estagiários do Convênio Amin Katbeh, Luiz Carlos Weinchutz e Raquel Mari Buba, graduandos do curso de geologia da UFPR, e ao desenhista Oto Laurentino Rosa, pela elaboração das figuras.

\section{REFERÊNCIAS BIBLIOGRÁFICAS}

ALMEIDA, F.F.M. de (1944) Collenia itapevensis. Um fóssil Pré-Cambriano no Estado de São Paulo. Boletim da Faculdade de Filosofia, Ciências e Letras da Universidade de São Paulo, 45:89-106 (Geografia, 1).

ALMEIDA, F.F.M. de (1956) Novas ocorrências de fósseis no Pré-Cambriano Brasileiro. Anais da Academia Brasileira de Ciências, 28(4):44-45.

BIGARELLA, J.J. (1947) Estudos preliminares na Série Açungui. I. Brecha calcária de Toquinhas. Arquivos de Biologia e Tecnologia, 2:41-61.

BIGARELLA, J.J.; SALAMUNI, R. (1956) Estudos preliminares da Série Açungui. V. Estruturas organógenas nos dolomitos da Formação Capiru (PR). Dusenia, 7(6):317-323.

BIGARELLA, J.J; SALAMUNI, $\mathbf{R}$. (1958) Estudos preliminares da Série Açungui. VIII - A Formação Votuverava. Boletim do Instituto de História Natural. Geologia, 2:1-6.

BIGARELLA, J.J.; SALAMUNI, $\mathbf{R}$. (1959) Planta geológica provisória de partes dos municípios de Rio Branco do Sul, Bocaiúva do Sul, Almirante Tamandaré e Colombo. Curitiba, Insti- tuto de Geologia - UFPR

BIGARELLA, J.J.; SALAMUNI, $R$. (1967) Geologia do Pré-Devoniano e intrusivas subsequentes da porção oriental do Estado do Paraná. Boletim Paranaense de Geociêneias, (23-25): 1-347.

BOUMA, A.H. (1962) Sedimentology of Some Flysch Deposits. Amsterdam, Elsevier. 264p.

BRUHN, C.H.L.; MORAES, M.A.S. (1989) Turbiditos da Formação Urucutuca na Bacia de Almada, Bahia: um laboratório de campo para estudo de reservatórios canalizados. Boletim de Geociências da Petrobrás, (3):235267.

BUENO, G.V. (1988) Modelo evolutivo para um paleo-canyon situado em uma bacia do tipo rift intracontinental - Bacia do Recôncavo - Brasil. In: CONGRESSO BRASILEIRO DE GEOLOGIA, 35, Belém, 1988. Anais, Belém, SBG, V.2, p. 854-868.

CAMPANHA, G.A.C.; BISTRICHI, C.A; ALMEIDA, M.A. (1987) Considerações sobre a organizaçăo litoestratigráfica e evolução tectônica da Faixa de Dobramentos Apiai. In: SIMPÓSIO SUL-BRASILEIRO DE GEOLOGIA, 3. Curitiba, 1987. Atas. Curitiba, SBG, V. 2 p. $725-742$.

CAMPANHA, G.A.C.; GIMENEZ FILHO, A; CAETANO, S.L.V.; PIRES, F.A.; DANTAS, A.S.L.; TEIXEIRA, A.L.; DEHIRA, L.F. (1986) Geologia e estratigrafia da região das folhas Iporanga e Gruta do Diabo, Vale do Ribeira, São Paulo. In: CONGRESSO BRASILEIRO DE GEOLOGIA, 34., Goiânia, 1986. Anais, Goiânia, SBG, V.2, p. 1058-1073.

CECILE, M.P.; CAMPBELL, F.H.A. (1978) Regressive stromatolite reefs and associated facies, middle Goulburn Group (Lower Proterozoic) in Kilohigok Basin, N.W.T; an example of 
environmental control of stromatolite form. Canadian Petroleum Geologists Bulletin, 26:237-267.

DIAS, M.V.F.; SALAZAR Jr., O. (1987) Geologia da Sequêencia Antinha - Grupo Açungui, PR. In: SIMPÓSIO SULBRASILEIRO DE GEOLOGIA, 3, Curitiba, 1987. Atas. Curitiba, SBG, V.1, p. 263-279.

DUKE, W.L. (1985) Hummocky crossstratification, tropical hurricanes, and intense winter storms. Sedimentology, 32:167-194.

EBERT, H. (1971) Observaç̋̃es sobre a litologia e subdivisão do "Grupo Setuva" no Estado do Paraná. In: CONGRESSO BRASILEIRO DE GEOLOGIA, 25, São Paulo, 1971. Anais. São Paulo, SBG, V.1, p.131-165.

FAIRCHILD, T.R. (1982) New stromatolites from the Upper Precambrian Açungui Group, eastern Paraná, Brazil and their potential stratigraphic use. Boletim IG-USP, Publicação Especial, 13:43-50.

FIORI, A.P. (1985) Avaliação preliminar do deslocamento dúctil das falhas da Lancinha e de Morro Agudo no Estado do Paraná. Boletim Paranaense de Geociências, 36:15-30.

FIORI, A.P. (1991) Tectônica e Estratigrafia do Grupo Acungui a norte de Curitiba. Săo Paulo, 261p. (Tese de Livre-Docência - Instituto de Geociências/USP).

FIORI, A.P. (1992) Tectônica e estratigrafia do Grupo Acungui-PR. Boletim IGUSP, Série Científica, 23:55-74.

FRIEDMAN, G.M:; SANDERS, J.E. (1967) Origin and occurrence of dolostones. In: CHILINGAR, G.V.; BISSELL, H.J.; FAIRBRIDGE, R.W. (eds). Carbonate Rocks. Amsterdam, Elsevier. p.267-348. (Developments in Sedimentology 9A).

FRITZSONS Jr., O; PERKARZ, G.F.;
FALCADE, D. (1982) Geologia e potencial econômico do Grupo Setuva (PR). In: CONGRESSO BRASILEIRO DE GEOLOGIA, 32., Salvador, 1987. Anais. Salvador, SBG, V.3, p.987. 1001

HALLAM, A. (1987) Interpretazione delle Facies e Stratigrafia. Tradução italiana - Pitagora Editrice - Bologna, 222p

HOFFMAN, P.F. (1967) Algal stromatolites-use in stratigraphic correlation and paleocurrent determination. Science, 157:1043-1045.

HOFFMAN, P. (1974) Shallow and deepwater stromatolites in lower Proterozoic platform-to-basin facies change, Great Slave Lake, Canada. The American Association of Petroleum Geologists Bulletin, 58:856-867

HOFFMAN, P. (1976) Stromatolite morphogenesis in Shark Bay, Western Australia. In: M.R. WALTER (ed.). Stromatolites: Amsterdam, Elsevier Sci.Pub.,p.261-273.

HOFMANN, H.J. (1969) Stromatolites from the Proterozoic Animikie and Sibley Groups, Ontario. Geological Survey of Canada Paper, 68-69:55p

JAMES, H.L. (1954) Sedimentary facies of iron mineral formation. Economic Geology, 49(3) 235-293.

JAMES, N.P. (1983) Reef environment. In: SCHOLLE, P.A. BEBOUT, D.G.; MOORE, C.H. (eds.). Carbonate Depositional Environments: The American Association of Petroleum Geologists. Memoir, 33:345-440

KENDALL, C.G.St.C.; SKIPWITH, St.S.P.A.d'E. (1968) Recent algal mats of a Persian Gulf Lagoon. Journal of Sedimentary Petrology, 38(4):10401058.

LALOU, C. (1957) Studies on bacterial precipitation of carbonates in sea water. Journal of Sedimentary Petrology, 27 
(2):190-195.

LEONARDOS, O.H. (1943) Nota sobre a geologia do distrito de Iporanga, SP. DNPM, REL.564.

LOGAN, W; REZAK, R; GINSBURG, R.N. (1964) Classification and environmental significance of algal stromatolites. Journal of Geology, 72, (1):6883.

MAACK, R. (1947) Breves noticias sobre a geologia dos Estados do Paraná e Santa Catarina. Arquivos de Biologia e Tecnologia (2): 63-154.

MARINI, O. J. (1970) Geologia da Folha de Rio Branco de Sul. Rio Claro, 190 p. (Tese de Doutorado - Unesp, Rio Claro, SP).

MARINI, O.J.; TREIN, E; FUCK, R.A. (1967) O Grupo Açungui no Estado do Paraná. Boletim Paranaense de Geociências, (23-25):307-324.

MARINI, O.J.; BIGARELLA, J.J. (1967) Rochas calcárias do Grupo Açungui. Boletim Paranaense de Geociências (23-25):157-181.

MARINI, O.J.; BOSIO, N.J. (1969) Estromatólitos algáceos em dolomitos do Grupo Açungui. Ciência e Cultura, 21:219-220.

MELFI, A.J; BETENCOURT, J; CORDANI, U. (1965) Reconhecimento fotogeológico de parte do Grupo Açungui. Bragancia, 24(34):447-474.

MORAES REGO, L.F. (1931) Estruturas antigas do Brasil. Anais da Escola de Minas de Ouro Preto, 22:27-85.

MORRIS, W.R.; BUBY-SPERA, C.J. (1988) Sedimentologic evolution of a submarine canyon in a forearc basin, Upper Cretaceous Rosario Formation, San Carlos, Mexico. The American Association of Petroleum Geologists Bulletin, 72(6):717-737.

OLIVEIRA, A.I.; LEONARDOS, O.H (1943) Geologia do Brasil. 2.ed. Rio de Janeiro, Ministério de Agricultura.
$813 p$.

PETRI, S.; SUGUIO, K. (1969) Sobre os metassedimentos do Grupo Açungui no extremo sul do Estado de São Paulo. São Paulo, 98p. Convênio USPDAEE.

PONTES, J.B. (1981) Investigaçōes e Potencialidades Econômicas da Formação Água Clara (PR). Curitiba, Mineropar (Relatório interno).

PONTES, J.B. (1982) Geologia e potencialidades econômicas da Formação Água Clara (PR). In: CONGRESSO BRASILEIRO DE GEOLOGIA, 32 ., Salvador, 1982. Anais. Salvador, SBG, v.3, p. $1002-1016$.

SCHOLL W.U. (1981) Geologia do Grupo Açungui na regiăo a noroeste de Rio Branco do Sul, Paraná. In: SIMPÓSIO REGIONAL DE GEOLOGIA, 3., São Paulo, 1981. Atas. São Paulo, SBG. v. 1, p. $170-184$.

SCHOLL, W.U.; LOPES, O.F ; SILVA, A.C.G.A; PROZZI, C.R. (1980) Geologia do Pré-Cambriano da região do anticlinal do Setuva (Município de Bocaiúva do Sul e Rio Branco do Sul-PR). In: CONGRESSO BRASILEIRO DE GEOLOGIA, 31., Camboriú, 1980. Anais. Camboriú, SBG. v. 5 , p. 3002 3012.

SHEPARD, F.P. (1981) Submarine canyons: multiple causes and long-time persistence. The American Association of Petroleum Geologists Bulletin, 65 : 1062-1077.

SHINN, E.A. (1983) Tidal flat environment. In: SCHOLLE, P.A. BEBOUT, D.G.; MOORE, C.H. (eds.). Carbonate Depositional Environments. The American Association of Petroleum Geologists. Memoir, 33:171-210

SOARES, P.C. (1987) Sequências tectosedimentares e tectônica deformadora no centro-oeste do Escudo Paranaense. In: SIMPÓSIO SUL-BRASILEIRO DE 
GEOLOGIA, 3., Curitiba, 1987. Atas. Curitiba, SBG. v.2, p. 743-771.

TAFT, W.H. (1967) Modern carbonate sediments. In: CHILINGAR, G.V.;
BISSELL, H.J.; FAIRBRIDGE, R.W (eds.). Carbonate rocks. Amsterdam, Elsevier. p.29-50. (Developments in Sedimentology 9A).

A.P.Fiori - Departamento de Geologia/UFPR - Caixa Postal 19.011 CEP 81.504 Curitiba, PR, Brasil. L.A.Gaspar - Convênio UFPR-MINEROPAR - Caixa Postal 19.011 CEP 81.504 Curitiba, PR. Brasil 